\title{
99mTc-Labeled Small-Molecule Inhibitors of Prostate-Specific Membrane Antigen: Pharmacokinetics and Biodistribution Studies in Healthy Subjects and Patients with Metastatic Prostate Cancer
}

\author{
Shankar Vallabhajosula ${ }^{1}$, Anastasia Nikolopoulou ${ }^{1}$, John W. Babich ${ }^{2}$, Joseph R. Osborne $^{1}$, Scott T. Tagawa ${ }^{1}$, Irina Lipai ${ }^{1}$, \\ Lilja Solnes ${ }^{1}$, Kevin P. Maresca ${ }^{2}$, Thomas Armor ${ }^{2}$, John L. Joyal ${ }^{2}$, Robert Crummet ${ }^{2}$, James B. Stubbs ${ }^{3}$, and \\ Stanley J. Goldsmith ${ }^{1}$ \\ ${ }^{I}$ New York Presbyterian Hospital and Weill Cornell Medical College, New York, New York; ${ }^{2}$ Molecular Insight Pharmaceuticals, Inc., \\ Cambridge, Massachusetts; and ${ }^{3}$ Radiation Dosimetry Systems, Inc, Alpharetta, Georgia
}

\begin{abstract}
Prostate-specific membrane antigen (PSMA) is a well-established target for developing radiopharmaceuticals for imaging and therapy of prostate cancer ( $\mathrm{PCa}$ ). We have recently reported that novel 99mTc-labeled small-molecule PSMA inhibitors bind with high affinity to PSMA-positive tumor cells in vitro and localize in PCa xenografts. This study reports the first, to our knowledge, human data in men with metastatic PCa and in healthy male subjects. Methods: Under an exploratory investigational new drug, using a cross-over design, we compared the pharmacokinetics, biodistribution, and tumor uptake of ${ }^{99 m T c-M I P-1404}$ and $99 \mathrm{mTc}-M I P-1405$ in 6 healthy men and 6 men with radiographic evidence of metastatic PCa. Wholebody images were obtained at $10 \mathrm{~min}$ and 1, 2, 4, and $24 \mathrm{~h}$. SPECT was performed between 3 and $4 \mathrm{~h}$ after injection. Results: Both agents cleared the blood rapidly, with MIP-1404 demonstrating significantly lower urinary activity (7\%) than MIP-1405 (26\%). Both agents showed persistent uptake in the salivary, lacrimal, and parotid glands. Uptake in the liver and kidney was acceptable for imaging at 1-2 h. In men with PCa, both agents rapidly localized in bone and lymph node lesions as early as $1 \mathrm{~h}$. SPECT demonstrated excellent lesion contrast. Good correlation was seen with bone scanning; however, more lesions were demonstrated with ${ }^{99 m T c-M I P-1404}$ and $99 \mathrm{~m}$ Tc-MIP-1405. The high-contrast images exhibited tumor-tobackground ratios from $3: 1$ to $9: 1$ at 4 and $20 \mathrm{~h}$. Conclusion: Compared with the standard-of-care bone scanning, ${ }^{99 m} \mathrm{Tc}-\mathrm{MIP}$ 1404 and 99mTc-MIP-1405 identified most bone metastatic lesions and rapidly detected soft-tissue $\mathrm{PCa}$ lesions including subcentimeter lymph nodes. Because ${ }^{99 m T c-M I P-1404}$ has minimal activity in the bladder, further work is planned to correlate imaging findings with histopathology in patients with high-risk metastatic PCa.
\end{abstract}

Key Words: prostate cancer; molecular imaging; prostate specific membrane antigen; ${ }^{99 m T c-M I P-1404 ; ~}{ }^{99 m T c-M I P-1405}$

J Nucl Med 2014; 55:1791-1798

DOI: 10.2967/jnumed.114.140426

Received Mar. 19, 2014; revision accepted Sep. 30, 2014.

For correspondence or reprints contact: Shankar Vallabhajosula, Department of Nuclear Medicine/Molecular Imaging, Weill Cornell Medical College of Cornell University, 525 East 68th St., STARR-207, New York, NY 10065.

E-mail: svallabh@med.cornell.edu

Published online Oct. 23, 2014.

COPYRIGHT (C 2014 by the Society of Nuclear Medicine and Molecular Imaging, Inc.
$\mathbf{I}$ is estimated that in 2014 there will be 233,000 new cases of prostate cancer (PCa) diagnosed and that 29,480 men will die of the disease $(1,2)$. When detected early, and when disease is localized to the prostate gland, the 5-y survival rate is nearly $100 \%$. However, once PCa has spread beyond the prostate, survival rates fall dramatically (2). The primary goal of staging is to define the anatomic extent of the tumor and to distinguish patients with organ-confined, locally invasive, or distant metastatic disease. Because accurate staging is critical to determine appropriate patient management, it follows that sensitive and specific localization of disease is a vital component of staging.

Prostate-specific antigen (PSA) testing cannot easily distinguish between low-risk and high-risk disease so as to appropriately direct treatment (3). Current diagnostic imaging modalities are suboptimal for detecting local disease, lymphatic spread, and distant metastatic disease. Confirmatory and disease staging/monitoring imaging methods, such as CT, MR imaging, bone scanning, and ${ }^{111}$ In-capromab pendetide imaging, suffer from poor sensitivity and specificity, significantly limiting their value in therapy-selection decisions $(4,5)$. Early detection of skeletal metastases is critical in the management of patients with high-risk PCa. Newly diagnosed patients with localized disease and no metastases may benefit from radical treatment with curative intent. In contrast, most guidelines recognize that patients with bone metastases should forgo local therapy to avoid unnecessary side effects and be treated with systemic therapy instead (6). Early metastases to bone may be missed with bone scanning because this technique relies on osteoblastic activity (mineralization) rather than detection of actual tumor cells (7). New molecular imaging approaches to more accurately assess the status of the disease and the progress of therapy may facilitate the selection of optimal treatment and improve patient outcomes.

PSMA (prostate-specific membrane antigen), also known as folate hydrolase I or glutamate carboxypeptidase II, a transmembrane, 750 amino acid, type II glycoprotein, is expressed virtually by all PCa (8), including metastatic PCa $(9,10)$. The expression of PSMA is further increased in poorly differentiated, metastatic, and hormone-refractory carcinomas $(11,12)$ as well as after androgendeprivation therapy (13) and in lymph node metastases (14). In addition, increased expression of PSMA in primary PCa correlates with other adverse traditional prognostic factors and independently 
predicts disease outcome $(11,15)$. Therefore, PSMA is an ideal target for developing imaging biomarkers for PCa (16-19).

PSMA is highly homologous to $N$-acetylated R-linked acidic dipeptidase, a neuropeptidase that produces the neurotransmitter glutamate and $\mathrm{N}$-acetylaspartate through the hydrolysis of $\mathrm{N}$-acetylaspartylglutamate (20-22). The investigators at Molecular Insight Pharmaceuticals (MIP) developed a series of novel glutamateurea (Glu-urea) amino acid heterodimeric inhibitors of PSMA for developing SPECT radiopharmaceuticals using ${ }^{123} \mathrm{I}$ or ${ }^{99 \mathrm{~m}} \mathrm{Tc}$ (23-26). It has been reported recently that 2 radioiodinated small molecules, ${ }^{123}$ I-MIP-1072 and ${ }^{123}$ I-MIP-1095, localized to lesions in bone and soft tissue that correlated with radiologic evidence of metastatic PCa (27). Because ${ }^{99 \mathrm{~m}} \mathrm{Tc}$ is the optimal radionuclide for developing SPECT radiopharmaceuticals, the investigators at MIP developed 2 high-affinity small-molecule PSMA inhibitors, MIP1404 and MIP-1405, which can be labeled with ${ }^{99 \mathrm{~m}} \mathrm{Tc}$ based on novel tricarbonyl chemistry $(25,26)$.

A particular advantage of an exploratory investigational new drug application (IND) is to rapidly bring similar compounds into the clinic to confirm preclinical data. To compare the biodistribution of ${ }^{99 m}$ Tc-MIP-1404 and ${ }^{99 m}$ Tc-MIP-1405 in the human subject, a phase I study in healthy human subjects and patients with metastatic PCa was performed on the basis of crossover design (28). We report here the results of this preliminary clinical study comparing the pharmacokinetics, biodistribution, tumor uptake, and radiation dosimetry of these 2 novel radiopharmaceuticals for PSMA and PCa imaging studies.

\section{MATERIALS AND METHODS}

\section{Study Design}

The study was an open-label, crossover design of 2 novel study drugs, ${ }^{99 \mathrm{~m}}$ Tc-MIP-1404 and ${ }^{99 \mathrm{~m}} \mathrm{Tc}-\mathrm{MIP}-1405$, involving 6 healthy controls and 6 patients with metastatic PCa. The sequence of study drugs was randomized. This phase I clinical study was performed under an exploratory IND at a single site (New York Weill Cornell Medical Center) and was approved by the institutional review board.

For healthy subjects, the inclusion criteria required normal rectal examination and a PSA of $4.0 \mathrm{ng} / \mathrm{mL}$ or less. For patients, the inclusion criteria required a documented history of prostate PCa by histopathology and radiologic evidence of metastatic disease with rising PSA. Patients were required to undergo bone scanning within $1 \mathrm{mo}$ and CT/MR imaging within the last 3 mo before the first dose administration of the study drug and have received no prior therapies within the last $3 \mathrm{mo}$. All subjects were required to use condoms or agree to use an acceptable form of birth control throughout the study period. Patients who received an IND drug within the past $30 \mathrm{~d}$ before enrollment and androgen-deprivation therapy or other forms of hormonal therapy for a period of $14 \mathrm{~d}$ before

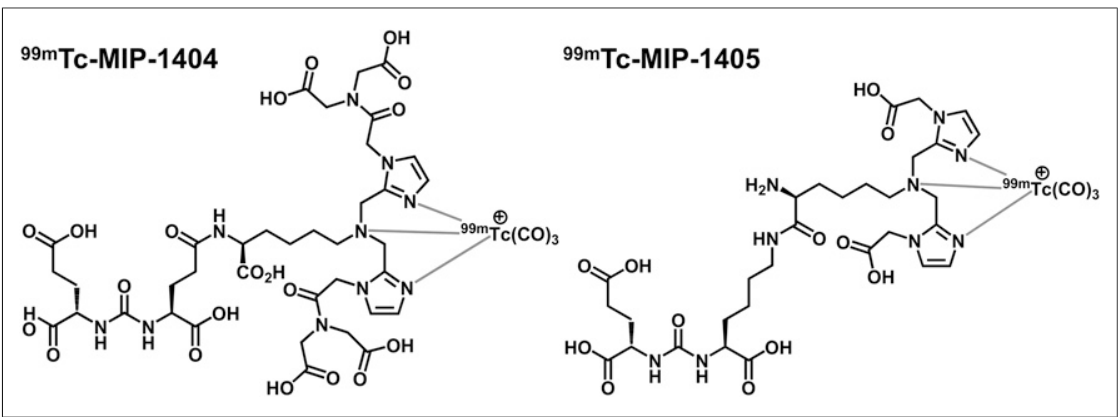

FIGURE 1. Structures of small-molecule inhibitors of PSMA, ${ }^{99 m}$ Tc-MIP-1404 and ${ }^{99 m T c-}$ MIP-1405. screening were excluded from this protocol. The subjects were invited to participate, after signing an informed consent form, and then were screened for eligibility. After undergoing baseline examinations, each subject received the first study drug and then was followed for $24 \mathrm{~h}$ to obtain whole-body planar $\gamma$-camera images and blood and urine samples for assay of radioactivity. SPECT/CT imaging of the pelvis, chest, or abdomen was performed at $3 \mathrm{~h}$. On completion of a 2-wk washout period, the same patient was administered the second study drug and underwent the evaluation described above.

\section{Study Drugs}

The synthesis of study drug precursors MIP-1404 and MIP-1405 (Fig. 1) and radiolabeling with ${ }^{99 \mathrm{~m}} \mathrm{Tc}$ were described previously $(25$, 26). These PSMA inhibitors were synthesized by the attachment of glutamate-urea-lysine and glutamate-urea-glutamate pharmacophore to novel, hydrophilic single-amino-acid chelate (29). The radiolabeling of the study drug precursors MIP-1404 and MIP-1405 with the novel intermediate $\left\{{ }^{99 \mathrm{~m}} \mathrm{Tc}(\mathrm{CO})_{3}\right\}^{+}$to form the desired metal complexes was accomplished in 2 steps using standard methodology $(25$, 29). IsoLink kits (Covidien) were used to generate the intermediate $\left\{{ }^{99 \mathrm{~m}} \mathrm{Tc}(\mathrm{CO})_{3}\right\}^{+}$in the final preparation of study drugs ${ }^{99 \mathrm{~m}} \mathrm{Tc}-\mathrm{MIP}-$ 1404 and ${ }^{99 m}$ Tc-MIP-1405 (Fig. 1). Briefly, 7.4 GBq (200 mCi) in 1-2 $\mathrm{mL}$ of sodium ${ }^{99 \mathrm{~m}} \mathrm{Tc}$ pertechnetate was added to an IsoLink kit, followed by the addition of study drug precursor $(100 \mu \mathrm{g}$ in $0.1 \mathrm{~mL})$. The mixture was incubated for $1 \mathrm{~h}$ at $100^{\circ} \mathrm{C}$. After neutralization and $\mathrm{C} 18$ Sep-Pack (Waters) purification, the study drug was collected in $1 \mathrm{~mL}$ of absolute ethanol and diluted with $9 \mathrm{~mL}$ of sterile saline. Subsequently, the final drug formulation was sterilized by passing through a $0.22 \mu \mathrm{m}$ membrane filter. The radiochemical and chemical purity of the final drug formulation was determined using high-performance liquid chromatography. In addition, tests for endotoxins and sterility were also performed on every batch of the study drug preparation.

\section{Administration of Study Drugs}

Each subject was randomly assigned to receive intravenously $740 \pm$ $111 \mathrm{MBq}$ of either ${ }^{99 \mathrm{~m} T c-M I P-1404}$ or ${ }^{99 \mathrm{~m} T c-M I P-1405}$, followed $2 \mathrm{wk}$ later by the second compound.

\section{Pharmacokinetics and Excretion}

Blood samples were collected at 0.1, 0.5, 1, 2, 4, 6, and $24 \mathrm{~h}$ after injection of ${ }^{99 \mathrm{~m} T c-M I P-1404}$ and ${ }^{99 \mathrm{~m} T c-M I P-1405}$; urine was collected and pooled at time intervals of $0-1,1-2,2-4$, and 4-24 h after dosing. Blood and urine samples were analyzed for ${ }^{99 \mathrm{~m} T c}$ activity using $\gamma$ well counting. The pharmacokinetic data were obtained with WinNonlin 4.1 software (Pharsight) as previously described (27). Blood and tissue concentration time data were computed and pharmacokinetic parameters, for example, maximum concentration in plasma $\left(\mathrm{C}_{\max }\right)$ and mean residence time (MRT) were generated. Total clearance was calculated as dose divided by area under the curve and steady-state volume of distribution as the product of total clearance and MRT. Distribution half-life $\left(\mathrm{T}_{1 / 2 \alpha}\right)$ and elimination half-life $\left(T_{1 / 2 \beta}\right)$ were obtained by fitting the 2-compartment model with bolus input and first-order output. The rate of urinary clearance and ${ }^{99 \mathrm{~m}} \mathrm{Tc}$ activity recovered in the urine was also computed by noncompartmental analysis (WinNonlin Model 211; Pharsight).

\section{Image Acquisition}

Whole-body scintigraphy was performed at 10 min and 1, 2, 4-6, and $24 \mathrm{~h}$ after injection. Anterior and posterior planar projections were acquired using a dual-head $\gamma$ camera (Infinia Hawkeye 4 GP-3; GE Healthcare) equipped 
TABLE 1

Demographics and Clinical Data for Patients with Metastatic PCa

\begin{tabular}{lcccccc}
\hline Patient no. & Age $(\mathrm{y})$ & $\begin{array}{c}\text { Baseline } \\
\text { PSA }(\mathrm{ng} / \mathrm{mL})\end{array}$ & $\begin{array}{c}\text { Dates of } \\
\text { 99mTc-MIP scans }\end{array}$ & $\begin{array}{c}\text { Date of original } \\
\text { diagnosis }\end{array}$ & $\begin{array}{c}\text { Prostatectomy } \\
\text { Prior radiation therapy }\end{array}$ \\
\hline 1 & 66 & 4.3 & $3 / 23 / 11 ; 4 / 6 / 11$ & $12 / 2 / 08$ & No & No \\
2 & 71 & 8.9 & $3 / 3 / 11 ; 3 / 17 / 11$ & $6 / 11 / 08$ & Yes (2008) & Yes $(2009) ; 7,020$ cGy \\
3 & 66 & 22.4 & $3 / 8 / 11 ; 3 / 22 / 11$ & $7 / 17 / 02$ & No & Yes (2004); dose not available \\
\hline 4 & 62 & 3.3 & $4 / 1 / 11 ; 4 / 15 / 11$ & $11 / 28 / 07$ & No & No \\
\hline 6 & 68 & 7.3 & $4 / 7 / 11 ; 4 / 25 / 11$ & $5 / 28 / 08$ & No & No \\
\hline
\end{tabular}

with low-energy high-resolution collimators. Scan velocity was incrementally slowed from $15 \mathrm{~cm} / \mathrm{min}$ at $10 \mathrm{~min} 1$ and $2 \mathrm{~h}$ after injection to $10 \mathrm{~cm} / \mathrm{min}$ at $4 \mathrm{~h}$ and $5 \mathrm{~cm} / \mathrm{min}$ at $24 \mathrm{~h}$. A matrix size of $256 \times 1,024$ pixels and a symmetric window of $20 \%$ centered on a $140-\mathrm{keV}$ photopeak were used for all acquisitions. A single imaging standard of approximately $18.5 \mathrm{MBq}(500 \mu \mathrm{Ci})$ was placed in the field of view for tion across all time points.

Tomographic SPECT of the abdomen, pelvis, or chest was obtained at approximately 3-5 $\mathrm{h}$ after injection. When available, SPECT/CT was anatomic localization using standard low-dose CT parameters. SPECT parameters consisted of a $360^{\circ}$ rotation, $30 \mathrm{~s}$ per stop, and a $3^{\circ}$ azimuth using a step-and-shoot technique. A matrix size of $128 \times 128$ and a symmetric window of $15 \%$ centered on a $140-\mathrm{keV}$ photopeak were used for all SPECT acquisitions. Raw SPECT data were reconstructed into 3-dimensional volumes and corrected for attenuation on a Hermes workstation (Hermes Medical Solutions) using ordered-subset expectation maximization iterative reconstruction methods ( 3 iterations $/ 30$ subsets) and filtered with a Butterworth filter (1.2 cutoff, 5 order). each whole-body acquisition to allow for decay and scan speed correcperformed to obtain measured attenuation-correction maps and to aid in

\section{Image Analysis}

Regions of interest (ROIs) were created over the imaging standard, tissues, and healthy organs on each anterior and posterior planar whole-body projection to extract count data corresponding to ${ }^{99 \mathrm{~m}} \mathrm{Tc}-$ MIP-1404 and ${ }^{99 m}$ Tc-MIP-1405 uptake. Count data, including the whole body, various organs, and urinary bladder contents, were collected. The mean count for each ROI at the first postdose image was divided by the mean count for the whole-body ROI at the first postdose image. The resulting ratio is expressed as a percentage and referred to as the percentage injected dose (\%ID) for that organ at the initial time point. Data describing the \%ID in each source organ were mathematically simulated using monoexponential functions with a nonlinear least-squares regression algorithm and SAAM II software (version 1.2; The Epsilon Group, a Division of MAS) (30). Additional analyses of target-to-background (T/B) count ratios were performed on planar and reconstructed SPECT images as previously described (27). T/B ratios for lesions within the SPECT field of view were calculated by obtaining counts from a circular 10-pixel ROI in the axial projection and an equal-sized ROI placed immediately adjacent as the background. The abnormal foci of activity on the scans (identified by the physicians) were used for measuring the radiotracer uptake. Only the lesions with 2 times the background were defined as positive uptake and included in the estimation of $\mathrm{T} / \mathrm{B}$ values. The $\mathrm{T} / \mathrm{B}$ ratios were measured at $1,2,4$, and $20 \mathrm{~h}$.
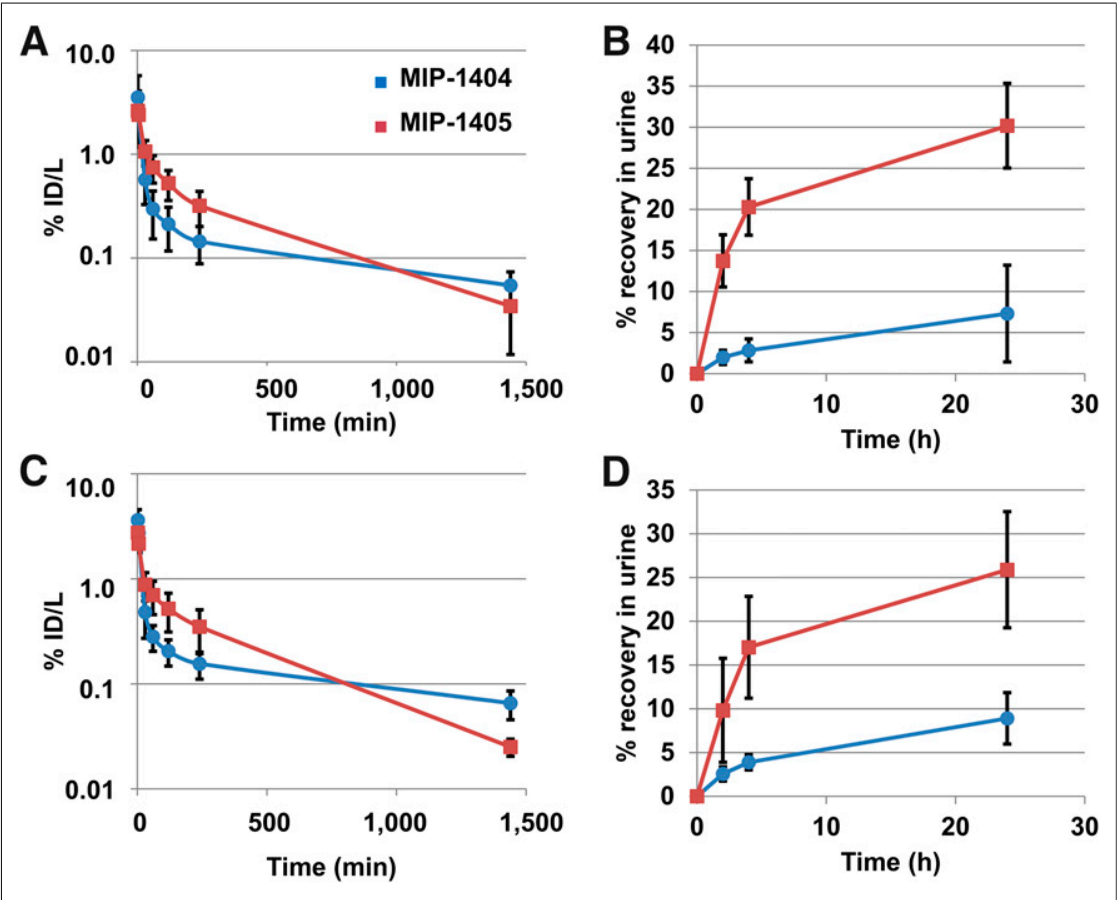

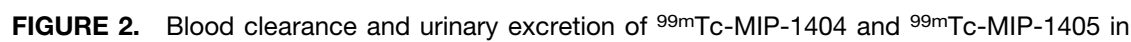
healthy subjects ( $A$ and $B$ ) and in patients with $\mathrm{PCa}(\mathrm{C}$ and $\mathrm{D})$.

\section{Organ Radiation-Absorbed Dose Estimates}

The OLINDA/EXM software was used to estimate radiation-absorbed dose to target organs $(31,32)$. The adult male model was used for all patients. The urinary bladder was assumed to be voided regularly at $4.8-\mathrm{h}$ intervals (i.e., 5 times per day). The urinary bladder residence times were computed using OLINDA/EXM implementation of the dynamic bladder model of Cloutier et al. (33). The small bowel and upper and lower large intestinal residence times were computed using the provided implementation of the ICRP publication 30 (34) gut transit model for the adult male. The radiation doses to salivary glands and tumors were determined using spheric $\mathrm{S}$ values as implemented in OLINDA/EXM.

\section{Safety}

Safety data were collected from treatmentemergent adverse event reports, pre- versus postinjection electrocardiograms, physical examinations, vital signs, and laboratory 
TABLE 2

Blood Pharmacokinetic Analysis of 99mTc-MIP-1404 and 99mTc-MIP-1405 in Healthy Subjects and Patients with PCa

\begin{tabular}{|c|c|c|c|c|}
\hline \multirow[b]{2}{*}{ Pharmacokinetic parameter } & \multicolumn{2}{|c|}{ 99mTc-MIP-1404 } & \multicolumn{2}{|c|}{ 99mTc-MIP-1405 } \\
\hline & Healthy subject & Patient & Healthy subject & Patient \\
\hline $\mathrm{T}_{\max }(\mathrm{h})$ & $0.04 \pm 0.02$ & $0.03 \pm 0.00$ & $0.06 \pm 0.03$ & $0.05 \pm 0.03$ \\
\hline $\mathrm{C}_{\max }(\mathrm{h})$ & $0.72 \pm 0.36$ & $0.87 \pm 0.33$ & $0.58 \pm 0.24$ & $0.60 \pm 0.15$ \\
\hline $\operatorname{AUC}_{(0-\infty)}(\mathrm{h} \times 37 \mathrm{KBq}[\mu \mathrm{Ci}] / \mathrm{mL})$ & $0.95 \pm 0.32$ & $1.34 \pm 0.59$ & $1.37 \pm 0.51$ & $1.44 \pm 0.49$ \\
\hline Clearance $(\mathrm{mL} / \mathrm{h} / \mathrm{kg})$ & $283 \pm 100$ & $198 \pm 70$ & $200 \pm 45$ & $181 \pm 104$ \\
\hline Vss (mL/kg) & $4,020 \pm 1,499$ & $3,356 \pm 1,371$ & $938 \pm 216^{*}$ & $824 \pm 602^{*}$ \\
\hline$T_{1 / 2}$ elimination $(h)$ & $13.53 \pm 2.18$ & $15.26 \pm 1.83$ & $5.68 \pm 0.97^{\star}$ & $5.12 \pm 0.84^{*}$ \\
\hline $\mathrm{MRT}_{(0-\infty)}(\mathrm{h})$ & $14.29 \pm 3.29$ & $16.95 \pm 3.03$ & $4.79 \pm 1.06^{\star}$ & $4.31 \pm 0.67^{\star}$ \\
\hline $\mathrm{T}_{1 / 2 \alpha}(\mathrm{h})$ & $0.250 \pm 2.5$ & $0.12 \pm 0.03$ & $0.42 \pm 0.30$ & $0.21 \pm 0.09$ \\
\hline $\mathrm{T}_{1 / 2 \beta}(\mathrm{h})$ & $13.2 \pm 2.79$ & $13.87 \pm 1.37$ & $5.51 \pm 0.79^{\star}$ & $5.03 \pm 0.81^{*}$ \\
\hline
\end{tabular}

${ }^{*}$ These values for ${ }^{99 m}$ Tc-MIP-1405 are statistically $(P<0.05)$ significant, compared with values obtained for ${ }^{99 m T c-M I P-1404 . ~}$

$\mathrm{C}_{\max }=$ maximum concentration in plasma; $\mathrm{AUC}_{(0-\infty)}=$ area under the curve; $\mathrm{Vss}=$ steady-state volume of distribution; $\mathrm{MRT}_{(0-\infty)}=$ mean residence time; $T_{1 / 2 \alpha}=$ distribution half-life; $T_{1 / 2 \beta}=$ elimination half-life.

measurements (including clinical chemistry, hematology, and urinalysis). The safety analysis was performed with data from all subjects. Adverse events were coded by the MedDRA dictionary (http://www. meddra.org/) and were summarized by occurrences and percentages of patients according to CTC (National Cancer Institute Common Terminology Criteria) grade, body system, preferred term, intensity, and causal relationship to study agent. SAS software (version 9.1; SAS Institute) was used for the safety analysis.

\section{RESULTS}

Preparation of ${ }^{99 \mathrm{mTc} M I P-1404}$ and ${ }^{99 m T c-M I P-1405}$

Each milliliter of the sterile, apyrogenic drug product $\left({ }^{99 \mathrm{~m} T c-}\right.$ MIP-1404 or ${ }^{99 m}$ Tc-MIP-1405) in physiologic saline contained approximately $92.5-185 \mathrm{MBq}$ of ${ }^{99 \mathrm{~m}} \mathrm{Tc}$ activity and $0.1 \mathrm{~mL}(0.79$ $\mathrm{mg}$ ) of ethanol. The radiochemical purity of the final drug formulation was $94.2 \% \pm 1.4 \%$ for ${ }^{99 m}$ Tc-MIP-1404 and $97.2 \%$ $\pm 1.7 \%$ for ${ }^{99 \mathrm{~m} T c-M I P-1405}$. The amount of free ${ }^{99 \mathrm{~m}} \mathrm{Tc}$ as pertechnetate was less than $1.0 \%$. The specific activity at the end of synthesis was about $37-44.4 \mathrm{MBq} / \mu \mathrm{g}$ of either drug product. The average dose injected in each subject was $784.4 \pm 59.2 \mathrm{MBq}$ and approximately $20 \mu \mathrm{g}$ of the drug product.

\section{Subject Population}

Eight healthy subjects and 7 patients were recruited in the protocol. Two of 8 healthy subjects dropped out of the study after the screening tests. Of the 7 patients recruited, 1 dropped out after the study and did not complete the protocol. The remaining 6 patients had a documented history of PCa by histopathology and had radiologic evidence of metastatic disease with rising PSA (Table 1). The PSA levels in 5 of 6 healthy controls were $0.8-3.3 \mathrm{ng} / \mathrm{mL}$, and only 1 healthy subject had a PSA of $9.3 \mathrm{ng} / \mathrm{mL}$. In patients with PCa, the PSA varied from 2.0 to 48.4 (13.8 \pm 12.3) $\mathrm{ng} / \mathrm{mL}$. Four of the 6 patients had intact prostate glands, and 3 of 6 patients had prior radiation therapy.

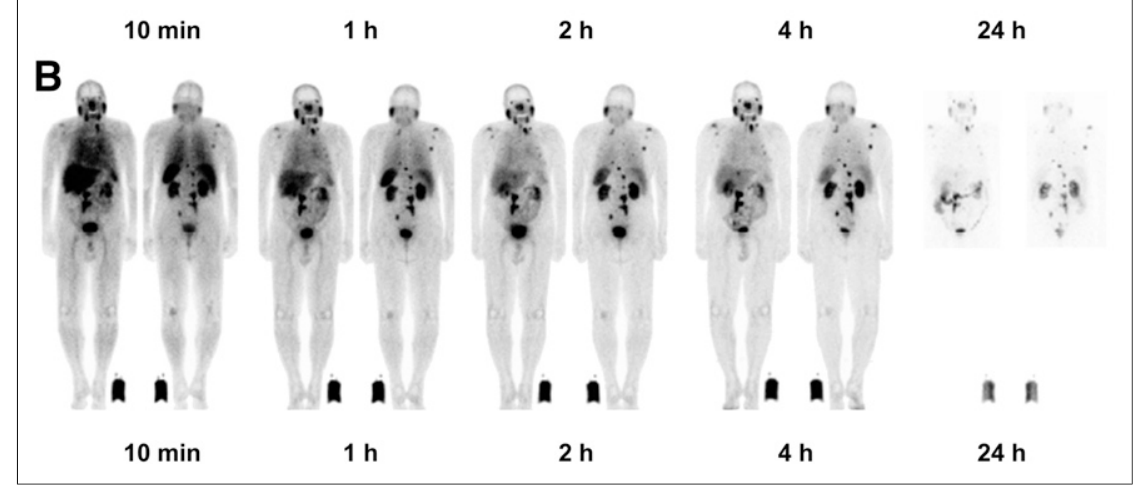

FIGURE 3. Whole-body planar images of ${ }^{99 m T c-M I P-1404 ~(A) ~ a n d ~}{ }^{99 m T c-M I P-1405 ~(B) ~ a t ~ d i f-~}$ ferent times after intravenous injection showing biodistribution in patient with metastatic PCa.

\section{Pharmacokinetics and Excretion}

After intravenous administration, the blood levels of ${ }^{99 m} \mathrm{Tc}-\mathrm{MIP}-1404$ and ${ }^{99 \mathrm{~m}} \mathrm{Tc}-$ MIP-1405 reached maximum concentration in plasma at the first time point $(5 \mathrm{~min})$ collected and declined rapidly in a biphasic fashion (Figs. 2A and 2B; Table 2). Both 99mTc-MIP-1404 and 99mTc-MIP-1405 were rapidly cleared from the vascular compartment and moved into the extravascular space, resulting in similar total blood exposure of ${ }^{99 \mathrm{~m}}$ Tc-MIP-1404 and ${ }^{99 \mathrm{~m}}$ Tc-MIP-1405 in both healthy subjects and $\mathrm{PCa}$ patients. 

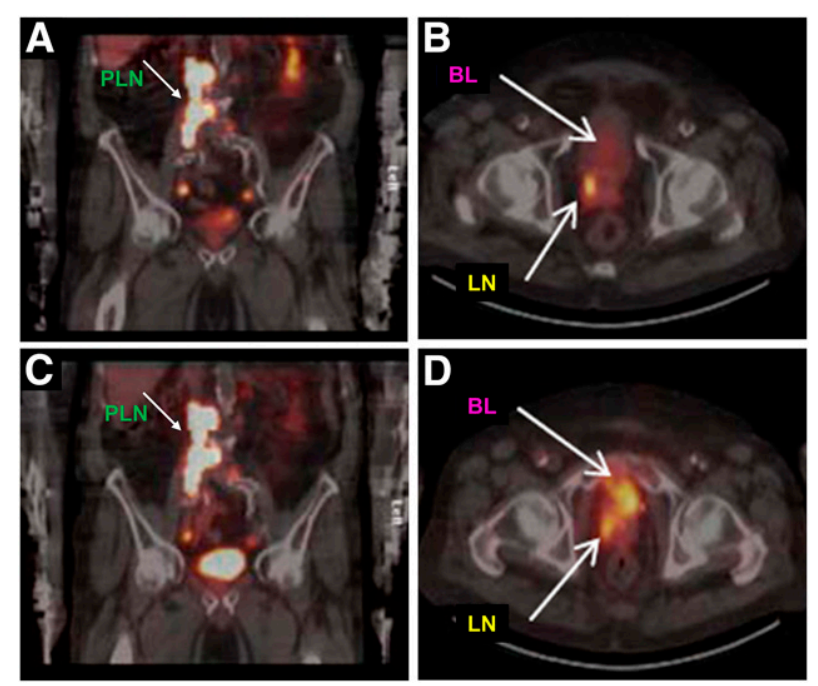

FIGURE 4. Differences in urinary excretion between 99mTc-MIP-1404 and 99mTc-MIP-1405. The planar and SPECT images of 99mTc-MIP-1404 (A and B) show minimal urinary excretion and bladder (BL) activity, compared with that of ${ }^{99 m T c-M I P-1405 ~(C ~ a n d ~ D) . ~ I m a g e s ~ a l s o ~ i d e n t i f y ~ m e t a s t a s i s ~ i n ~ l y m p h ~}$ node (LN) in pelvis and paraaortic lymph nodes (PLN).

No apparent differences in any pharmacokinetic parameters were noted when comparing healthy subjects with PCa patients. Preliminary analysis, however, indicates a significant difference $(P<$ $0.05)$ in steady-state volume of distribution, half-life, MRT, and $\mathrm{T}_{1 / 2 \beta}$ when comparing these 2 agents between healthy subjects and PCa patients. By $24 \mathrm{~h}$, approximately 5\%-10\% of the injected dose of ${ }^{99 \mathrm{~m}}$ Tc-MIP-1404 and $25 \%-30 \%$ of the injected dose of ${ }^{99 \mathrm{~m}} \mathrm{Tc}-$ MIP-1405 was present in the urine (Figs. 2B and 2D).

\section{Imaging Studies and Tissue Distribution}

Typical whole-body planar images for a patient administered 99mTc-MIP-1404 and 99mTc-MIP-1405 through $24 \mathrm{~h}$ after injection are depicted in Figure 3. In healthy subjects and in patients with metastatic $\mathrm{PCa}$, uptake of both agents was evident in the parotid and salivary glands, liver, kidneys, and gastrointestinal tract. As shown in Figure 3, the whole-body clearance of ${ }^{99 \mathrm{~m}} \mathrm{Tc}-$ MIP-1405 was significantly greater and the liver and kidney uptake was much lower than those of ${ }^{99 m}$ Tc-MIP-1404. Significantly

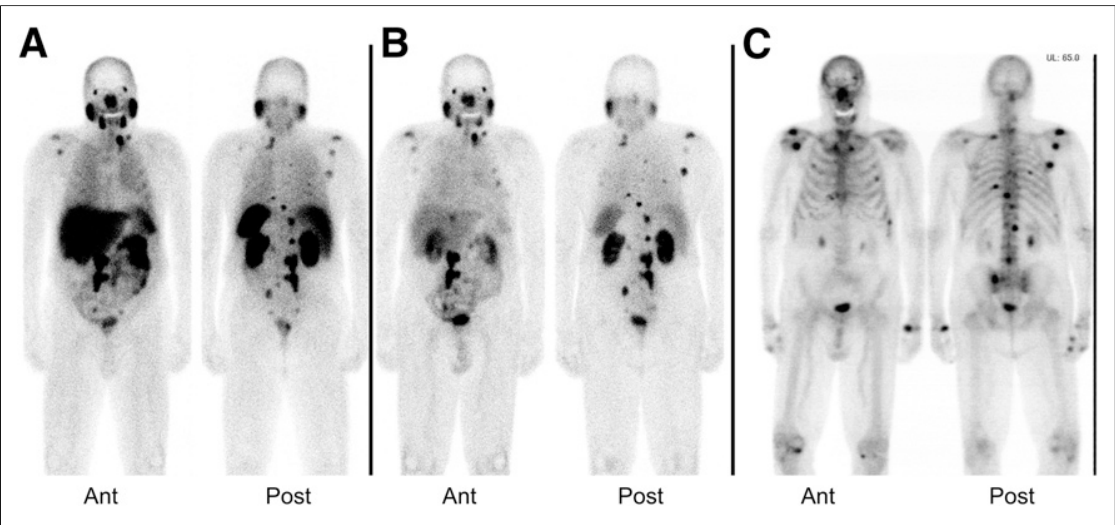

FIGURE 5. Tumor uptake of ${ }^{99 m}$ Tc-MIP-1404 (A) or ${ }^{99 m T c-M I P-1405 ~(B) ~ a t ~} 4 \mathrm{~h}$ in patient with metastatic $\mathrm{PCa}$, compared with that of standard bone scan (C). Images also show uptake of radiotracer in normal parotid and salivary glands. Ant $=$ anterior; Post $=$ posterior. lower uptake was seen in the bladder with ${ }^{99 m}$ Tc-MIP-1404 than with ${ }^{99 \mathrm{~m}}$ Tc-MIP-1405, as illustrated in planar images in Figure 3 and SPECT/CT images in Figure 4.

ROIs were created over the imaging standard, tissues, and normal organs on the anterior and posterior planar whole-body images of each subject to extract count data corresponding to the in vivo distribution of these 2 agents. ${ }^{99 \mathrm{~m}} \mathrm{Tc}-\mathrm{MIP}-1405$ was cleared from the whole body more rapidly than ${ }^{99 m}$ Tc-MIP-1404 (Supplemental Fig. 1; supplemental materials are available at http://jnm.snmjournals.org). With ${ }^{99 m}$ Tc-MIP-1405, $63 \%$ ID remained in the body at $4 \mathrm{~h}$ and 27 $\%$ ID at $20 \mathrm{~h}$. In contrast, ${ }^{99 \mathrm{~m}} \mathrm{Tc}-\mathrm{MIP}-1404$ was cleared from the body more slowly, resulting in increased soft-tissue uptake. At $4 \mathrm{~h}$, $93 \%$ ID remained in the body, and at $20 \mathrm{~h} 84 \%$ ID remained. In all organs examined (kidneys, liver, brain, salivary glands, heart, lungs, and spleen), greater retention was observed with ${ }^{99 \mathrm{~m}} \mathrm{Tc}-\mathrm{MIP}-1404$ than with ${ }^{99 m}$ Tc-MIP-1405. Minimal uptake was detected in the brain and heart. Because the whole-body clearance and biodistribution of these 2 agents are similar in both healthy subjects and patients with $\mathrm{PCa}$, the values (Supplemental Fig. 1) represent the mean $\pm \mathrm{SD}$ of all 12 subjects in the study.

\section{Detection of PCa Metastatic Lesions}

In patients with $\mathrm{PCa}$, suspected metastatic lesions present in the bone, lymph nodes, and prostate bed were observed with both ${ }^{99 \mathrm{~m}}$ Tc-MIP-1404 and ${ }^{99 \mathrm{~m}}$ Tc-MIP-1405 within $10 \mathrm{~min}$ after injection. The planar images, however, showed better contrast at 2 and $4 \mathrm{~h}$ after injection. The uptake in metastatic lesions and the salivary glands was seen even at $24 \mathrm{~h}$ after injection. The planar images in a patient with metastatic PCa (patient 6, Table 1) demonstrate that both ${ }^{99 \mathrm{~m}} \mathrm{Tc}$ agents identified the abnormal metastatic foci detected by the standard-of-care bone scan (Fig. 5). In 5 of 6 patients, ${ }^{99 m}$ Tc PSMA planar scans clearly identified all the metastatic lesions previously detected by bone scanning. In one of the patients (patient 2, Table 1), both ${ }^{99 \mathrm{~m}} \mathrm{Tc}$ agents identified more abnormal foci than the bone scanning performed 2 mo earlier. A repeated bone scan obtained 3 mo after the ${ }^{99 \mathrm{~m} T c-M I P-}$ 1404 PSMA scan identified additional metastatic sites not seen in the first bone scan (Fig. 6).

As the blood and soft-tissue background cleared, T/B ratios derived from whole-body planar images increased from an average value of $3: 1$ at $1 \mathrm{~h}$ to $9: 1$ at approximately $20 \mathrm{~h}$ after injection for both these agents (Fig. 7). Although higher total uptake of ${ }^{99 \mathrm{~m} T c-M I P-1404}$ was detected in suspected lesions, there were no statistically significant differences in $T / B$ ratios for either of these agents at 2 and $4 \mathrm{~h}$, ideal time points for imaging studies.

\section{Radiation Dosimetry}

The radiation-absorbed dose for organs was estimated in units of $\mathrm{mGy} / \mathrm{MBq}$. The complete radiation dose estimates for various organs for both ${ }^{99 \mathrm{~m}} \mathrm{Tc}-\mathrm{MIP}-1404$ and ${ }^{99 \mathrm{~m}} \mathrm{Tc}-$ MIP-1405 are shown in Table 3. The mean effective dose is $0.0088 \mathrm{mSv} / \mathrm{MBq}$ with 99mTc-MIP-1404 and $0.0079 \mathrm{mSv} / \mathrm{MBq}$ with 99mTc-MIP-1405. For a $740-\mathrm{MBq}(20 \mathrm{mCi})$ administered dose, the mean effective dose is about $6.5 \mathrm{mSv}$ for ${ }^{99 \mathrm{~m} T c-M I P-1404}$ and 5.82 $\mathrm{mSv}$ for ${ }^{99 \mathrm{~m}} \mathrm{Tc}-\mathrm{MIP}-1405$. The critical organ for ${ }^{99 \mathrm{~m}} \mathrm{Tc}-\mathrm{MIP}-1404$ is the kidney $(54.24$ $\mathrm{mGy} / 740 \mathrm{MBq}$ [5.42 $\mathrm{rads} / 20 \mathrm{mCi}]$ ) and for 


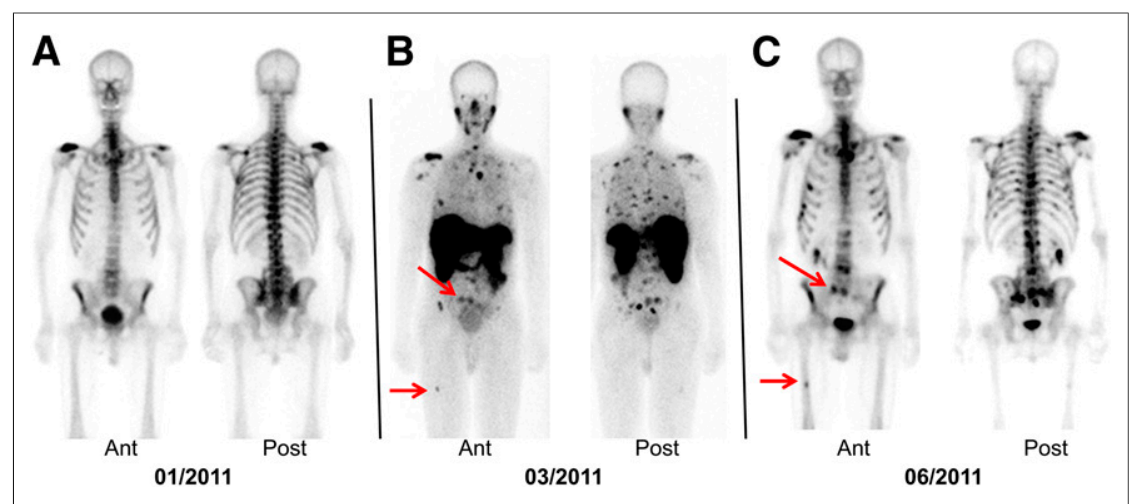

FIGURE 6. Comparison of $99 \mathrm{mTC}-\mathrm{MIP}-1404$ scan with bone scans in patient with metastatic PCa. PSMA imaging with 99mTc-MIP-1404 (in March) detected more metastatic lesions than 2 bone scans obtained either before (in January) or after (in June) PSMA scan. Ant = anterior; Post = posterior. Metastatic sites (red arrows) shown in PSMA scan (B) were detected by bone scan (C) performed 3 mo after PSMA scan.

99mTc-MIP-1405 the urinary bladder wall (32.1 mGy/740 MBq [3.21 rads/20 $\mathrm{mCi}]$ ). With both agents, the salivary gland is 1 of the organs receiving the largest radiation-absorbed dose along with the kidneys and the urinary bladder wall.

\section{Safety}

Both ${ }^{99 m}$ Tc-MIP-1404 and ${ }^{99 m}$ Tc-MIP-1405 were well tolerated in this study. There were no treatment-emergent adverse events and serious adverse events reported in this study. Clinical laboratory, vital signs, and electrocardiogram results were unremarkable, with no clinically significant differences between the 2 study drugs.

\section{DISCUSSION}

PSMA was one of the first PCa biomarkers successfully cloned and has been the subject of intense clinical inquiry as an imaging and therapeutic agent since 1993 (9). We recently reported the potential clinical utility of ${ }^{123}$ I-labeled small-molecule PSMA inhibitors for imaging PCa (27). Because the ${ }^{99 \mathrm{~m}} \mathrm{Tc}$ atom has the ideal nuclear properties of $\gamma$ energy (140-keV photon) and half-life $(6 \mathrm{~h})$, as well as its convenient availability from commercial generators, it has become the most ideal radionuclide to develop radiopharmaceuticals for SPECT. The polyvalent nature of technetium, however, demands that due consideration is given to the chemical approach used for its incorporation into a targeting ligand. How the metal is bound can greatly influence the overall pharmacologic character and biologic fate of the complex, by altering the overall charge, polarity, hydrophobicity, and steric bulk. The chelate, the metal-chelate complex, and the nature of the outer solvation sphere of the metal chelate complex all directly or indirectly influence the performance of such a radiolabeled ligand in regards to its intended clinical use (25). Maresca et al. have previously reported the development of a single-amino-acid-based radiolabeling platform, constructed from derivatized amino acids modified to provide 3 donor groups (L3) for chelation to the $\left\{\mathrm{M}(\mathrm{CO})_{3}\right\}^{+1}$ core (Fig. 1). On the basis of this chemistry, ${ }^{99 \mathrm{~m} T c}$ labeling of MIP-1404 and MIP-1405 (>90\%) was achieved with only $100 \mu \mathrm{g}$ of ligand $\left(\sim 10^{-5} \mathrm{M}\right)$, and the ${ }^{99 \mathrm{~m}} \mathrm{Tc}$ complexes were stable $(>90 \%)$ for $24 \mathrm{~h}(25)$.

Although both ${ }^{99 \mathrm{~m}} \mathrm{Tc}$ agents are based on the glutamate-urea amino acid core and display similar PSMA binding affinities (26), significantly different pharmacokinetic parameters were observed in the human studies reported here, most likely because of modest structural differences affecting hydrophobicity and protein binding. After intravenous administration, blood levels of 99m Tc-MIP-1404 and ${ }^{99 m}$ Tc-MIP-1405 declined rapidly in a biphasic fashion (Figs. $2 \mathrm{~A}$ and $2 \mathrm{C}$; Table 2) from the vascular compartment and moved into the extravascular space, resulting in similar total blood exposure in both healthy controls and patients with PCa. However, on the basis of serial imaging studies (Fig. 3), ${ }^{99 \mathrm{~m} T c-}$ MIP-1405 was cleared from the whole body, via the kidneys, more rapidly than 99m Tc-MIP-1404. At $4 \mathrm{~h}$ after injection, $37 \%$ of ${ }^{99 m}$ Tc-MIP-1405 activity cleared from the whole body, compared with only $7 \%$ of ${ }^{99 m}$ Tc-MIP-1404 activity. Also the cumulative urinary activity was significantly higher at 4 and $24 \mathrm{~h}$ for ${ }^{99 \mathrm{~m}} \mathrm{Tc}-$ MIP-1405 than for ${ }^{99 m}$ Tc-MIP-1404 (Figs. 2B and 2D). These results of the in vivo distribution and urinary excretion suggest that ${ }^{99 \mathrm{~m}} \mathrm{Tc}-\mathrm{MIP}-1404$ may be more suitable for imaging lesions in the pelvis, whereas ${ }^{99 \mathrm{~m}} \mathrm{Tc}-\mathrm{MIP}-1405$ may provide better contrast for imaging metastatic sites outside the pelvis.

In all 6 patients with metastatic PCa, both ${ }^{99 m}$ Tc-MIP-1404 and ${ }^{99 m}$ Tc-MIP-1405 localized to lesions in bone and soft tissue that correlated with radiologic evidence of metastatic disease identified by the bone scan (Figs. 5 and 6). Between 1 and $4 \mathrm{~h}$ after injection, the T/B ratios (Fig. 7) were similar for both agents even though the image contrast outside the pelvis appears to be slightly better with 99mTc-MIP-1405 (Figs. 3 and 5). In a 71-y-old patient who had prior prostatectomy and with a rising PSA $(1.37-8.9 \mathrm{ng} / \mathrm{mL}$ over a period of 4 mo), PSMA imaging with ${ }^{99 m}$ Tc-MIP-1404 (in March) detected more metastatic lesions earlier than with the 2 bone scans obtained either before (in January) or after (in June) the PSMA scanning (Fig. 6). This observation suggests that PSMAtargeted molecular imaging may have the potential to identify disease progression earlier than the standard bone scanning. In addition, in several patients, significant uptake was also observed in lymph nodes smaller than $10 \mathrm{~mm}$, considered normal by size threshold criteria used in cross-sectional imaging such as CT and MR. Although histologic confirmation of the disease in the lymph nodes is needed, these observations suggest an improvement in the sensitivity of lesion detection with molecular imaging

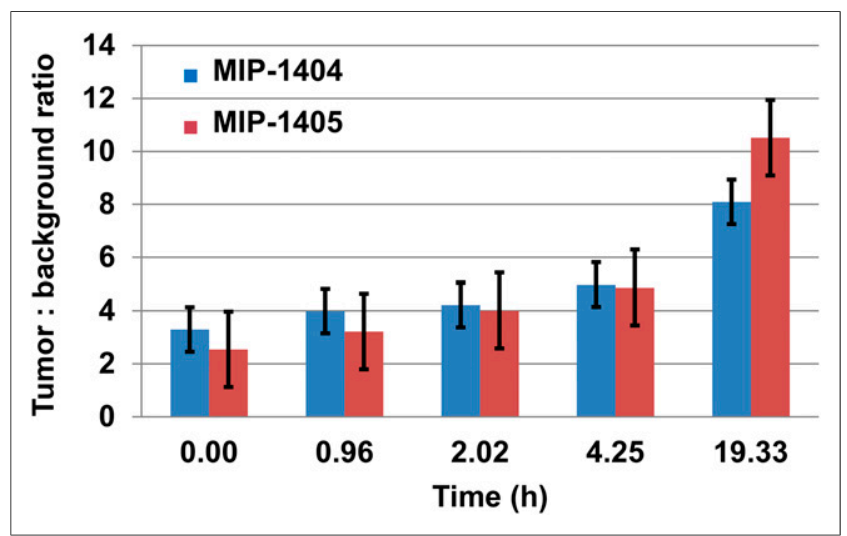

FIGURE 7. T/B ratios of ${ }^{99 m}$ Tc-MIP-1404 and ${ }^{99 m}$ Tc-MIP-1405 in patients with metastatic $\mathrm{PCa}$. 
TABLE 3

Radiation Dosimetry

\begin{tabular}{|c|c|c|c|c|c|c|}
\hline \multirow[b]{2}{*}{ Organ } & \multicolumn{3}{|c|}{ 99mTc-MIP-1404 } & \multicolumn{3}{|c|}{ 99mTc-MIP-1405 } \\
\hline & mGy/MBq & $\mathrm{mGy} / 740 \mathrm{MBq}$ & $\mathrm{Rad} / 20 \mathrm{mCi}$ & mGy/MBq & $\mathrm{mGy} / 740 \mathrm{MBq}$ & $\mathrm{Rad} / 20 \mathrm{mCi}$ \\
\hline Kidneys & 7.33E-02 & 54.24 & 5.42 & 3.63E-02 & 26.86 & 2.69 \\
\hline Salivary glands (77 g) & $5.24 \mathrm{E}-02$ & 38.78 & 3.88 & $3.01 \mathrm{E}-02$ & 22.27 & 2.23 \\
\hline Spleen & $2.18 \mathrm{E}-02$ & 16.13 & 1.61 & $9.94 \mathrm{E}-03$ & 7.36 & 0.74 \\
\hline Thyroid & $1.95 \mathrm{E}-02$ & 14.43 & 1.44 & 1.33E-02 & 9.84 & 0.98 \\
\hline Liver & $1.61 \mathrm{E}-02$ & 11.91 & 1.19 & $6.68 \mathrm{E}-03$ & 4.94 & 0.49 \\
\hline Upper large intestine wall & $1.61 \mathrm{E}-02$ & 11.91 & 1.19 & $1.25 \mathrm{E}-02$ & 9.25 & 0.93 \\
\hline Urinary bladder wall & $1.27 \mathrm{E}-02$ & 9.40 & 0.94 & 4.34E-02 & 32.12 & 3.21 \\
\hline Lower large intestine wall & $1.16 \mathrm{E}-02$ & 8.58 & 0.86 & $1.08 \mathrm{E}-02$ & 7.99 & 0.80 \\
\hline Small intestine & $1.04 \mathrm{E}-02$ & 7.70 & 0.77 & $8.30 \mathrm{E}-03$ & 6.14 & 0.61 \\
\hline Gallbladder wall & $9.70 \mathrm{E}-03$ & 7.18 & 0.72 & $5.54 \mathrm{E}-03$ & 4.10 & 0.41 \\
\hline Adrenals & 8.87E-03 & 6.56 & 0.66 & $4.95 \mathrm{E}-03$ & 3.66 & 0.37 \\
\hline Pancreas & 8.36E-03 & 6.19 & 0.62 & $4.81 \mathrm{E}-03$ & 3.56 & 0.36 \\
\hline Osteogenic cells & 8.36E-03 & 6.19 & 0.62 & $6.44 \mathrm{E}-03$ & 4.77 & 0.48 \\
\hline Lungs & $6.52 \mathrm{E}-03$ & 4.82 & 0.48 & $3.88 \mathrm{E}-03$ & 2.87 & 0.29 \\
\hline Ovaries & 6.37E-03 & 4.71 & 0.47 & $6.51 \mathrm{E}-03$ & 4.82 & 0.48 \\
\hline Uterus & $5.98 \mathrm{E}-03$ & 4.43 & 0.44 & 8.34E-03 & 6.17 & 0.62 \\
\hline Stomach wall & $5.74 \mathrm{E}-03$ & 4.25 & 0.42 & $3.72 \mathrm{E}-03$ & 2.75 & 0.28 \\
\hline Heart wall & $5.61 \mathrm{E}-03$ & 4.15 & 0.42 & $3.53 E-03$ & 2.61 & 0.26 \\
\hline Red marrow & $4.08 \mathrm{E}-03$ & 3.02 & 0.30 & $3.02 \mathrm{E}-03$ & 2.23 & 0.22 \\
\hline Muscle & $3.52 \mathrm{E}-03$ & 2.60 & 0.26 & $2.86 \mathrm{E}-03$ & 2.12 & 0.21 \\
\hline Thymus & $3.05 \mathrm{E}-03$ & 2.26 & 0.23 & $2.22 \mathrm{E}-03$ & 1.64 & 0.16 \\
\hline Testes & $2.59 \mathrm{E}-03$ & 1.92 & 0.19 & $3.20 \mathrm{E}-03$ & 2.37 & 0.24 \\
\hline Breasts & $2.27 \mathrm{E}-03$ & 1.68 & 0.17 & $1.60 \mathrm{E}-03$ & 1.18 & 0.12 \\
\hline Skin & $2.01 \mathrm{E}-03$ & 1.49 & 0.15 & $1.58 \mathrm{E}-03$ & 1.17 & 0.12 \\
\hline Brain & $1.23 \mathrm{E}-03$ & 0.91 & 0.09 & $9.14 \mathrm{E}-04$ & 0.68 & 0.07 \\
\hline Total body & $4.46 \mathrm{E}-03$ & 3.30 & 0.33 & $3.29 E-03$ & 2.43 & 0.24 \\
\hline Effective dose equivalent & $1.25 \mathrm{E}-02$ & 9.25 & 0.93 & $1.01 \mathrm{E}-02$ & 7.47 & 0.75 \\
\hline Effective dose (mSv/MBq) & $8.78 \mathrm{E}-03$ & 6.50 & 0.65 & 7.87E-03 & 5.82 & 0.58 \\
\hline
\end{tabular}

using small-molecule ${ }^{99 \mathrm{~m}}$ Tc-labeled PSMA inhibitors. The phase I data with ${ }^{99 \mathrm{~m}} \mathrm{Tc}$ agents described here are consistent with preclinical studies in PSMA-expressing LNCaP xenografts. In addition, the biodistribution, blood clearance, and tumor uptake profiles of ${ }^{99 m}$ Tc-MIP-1404 and ${ }^{99 m}$ Tc-MIP-1404 are also similar to those of 2 other high-affinity PSMA inhibitors, MIP-1092 and MIP-1095 labeled with ${ }^{123} \mathrm{I}$, previously studied in healthy subjects and subjects with advanced metastatic cancer (27).

Recently, several PET radiopharmaceuticals based on smallmolecule PSMA inhibitors labeled with ${ }^{18} \mathrm{~F}$ or ${ }^{68} \mathrm{Ga}$ have been reported $(18,19,35)$. Initial phase I studies with ${ }^{18} \mathrm{~F}-\mathrm{N}-[\mathrm{N}-[(S)-1,3-$ dicarboxypropyl]carbamoyl]-4- ${ }^{18} \mathrm{~F}$-fluorobenzyl-L-cysteine $\left({ }^{18} \mathrm{~F}-\right.$ DCFBC) demonstrated the potential of targeting PSMA for the detection of metastatic PCa. However, there was decreasing but moderately persistent blood-pool and liver activity. The slow rise in decay-corrected hepatic uptake suggests the possibility of some hepatic excretion of ${ }^{18} \mathrm{~F}$-DCFBC with a long biologic elimination period (18). In addition, unlike ${ }^{99 \mathrm{~m}} \mathrm{Tc}$ agents reported here, PET scans with ${ }^{18} \mathrm{~F}-\mathrm{DCFBC}$ did not show any uptake by the parotid and salivary glands. Initial clinical studies with the ${ }^{68} \mathrm{Ga}-N, N^{\prime}$-bis[2hydroxy-5-(carboxyethyl)benzyl]ehtylenediamine- $N, N^{\prime}$-diacetic acid radiotracer, however, showed in vivo distribution similar to the ${ }^{99 \mathrm{~m}} \mathrm{Tc}$ agents reported here. The PET scans showed significant ${ }^{68} \mathrm{Ga}$ uptake in the salivary glands and kidneys only and to a lesser extent in lacrimal glands, liver, spleen, and bowel as well as normal prostate tissue (19). In a study comparing ${ }^{68} \mathrm{Ga}$-PSMA PET with ${ }^{18} \mathrm{~F}$ fluorocholine PET, it was reported that ${ }^{68} \mathrm{Ga}$-PSMA can detect $\mathrm{PCa}$ relapses and metastases with significantly improved contrast when compared with fluorocholine (19).

The results of the present study demonstrate that targeting PSMA with both ${ }^{99 \mathrm{~m}}$ Tc-MIP-1404 and ${ }^{99 \mathrm{~m}} \mathrm{Tc}-\mathrm{MIP}-1405$ facilitates the detection of radiologically proven $\mathrm{PCa}$ in bone, lymph nodes, and the prostate gland. Also the radiation dosimetry from a single administration of a diagnostic dose for either of these agents is only around $6 \mathrm{mSv}$, which is similar to the radiation dose from the conventional bone scan in nuclear medicine. Although both of these agents showed minimal or no uptake in the prostate of healthy male subjects, only ${ }^{99 \mathrm{~m}}$ Tc-MIP-1404 showed minimal urinary excretion. This finding suggested that ${ }^{99 \mathrm{~m}} \mathrm{Tc}-\mathrm{MIP}-1404$ may have distinct advantage for detecting PCa in the gland and in the pelvis at early stages of the disease. On the basis of these results, a preliminary phase I study and a multicenter phase II study were 
conducted in high-risk PCa patients scheduled for prostatectomy and extended pelvic node lymph node dissection $(36,37)$.

\section{CONCLUSION}

Microdosing studies under an exploratory IND allowed for the assessment of preliminary pharmacokinetics and pharmacodynamics for two ${ }^{99 \mathrm{~m}}$ Tc-labeled small molecules, MIP-1404 and MIP-1405, that bind to PSMA with high affinity. After intravenous administration, blood levels of ${ }^{99 m}$ Tc-MIP-1404 and ${ }^{99 m}$ Tc-MIP1405 declined rapidly, and high-contrast planar and SPECT scans were obtained within $1-2 \mathrm{~h}$ after injection. In patients with metastatic PCa, both ${ }^{99 m}$ Tc-MIP-1404 and ${ }^{99 m}$ Tc-MIP-1405 localized to lesions in bone and soft tissue that correlated with radiologic evidence of metastatic disease identified by the bone scan. Because ${ }^{99 \mathrm{~m} T c-M I P-1404}$ showed minimal urinary excretion, it had a distinct advantage for detecting $\mathrm{PCa}$ in the gland and pelvis at early stages of the disease and was selected for phase II studies to determine sensitivity and specificity to detect $\mathrm{PCa}$ in high-risk patients.

\section{DISCLOSURE}

The costs of publication of this article were defrayed in part by the payment of page charges. Therefore, and solely to indicate this fact, this article is hereby marked "advertisement" in accordance with 18 USC section 1734 . The single center phase I study described in this article was funded by the Molecular Insight Pharmaceuticals (MIP). No other potential conflict of interest relevant to this article was reported.

\section{REFERENCES}

1. Siegel R, Ma J, Zou Z, Jemal J. Cancer statistics 2014. CA Cancer J Clin. 2014;64:9-29.

2. Surveillance Research Program, NCI. SEER Stat Fact Sheets: Prostate Cancer. National Cancer Institute website. http://seer.cancer.gov/statfacts/html/prost. html. Accessed October 3, 2014.

3. Shariat SF, Scardino PT, Lilja H. Screening for prostate cancer: an update. Can J Urol. 2008;15:4363-4374.

4. Hricak H, Choyke PL, Eberhardt SC, Leibel SA, Scardino PT. Imaging prostate cancer: a multidisciplinary perspective. Radiology. 2007;243:28-53.

5. Hou AH, Swanson D, Barqawi AB. Modalities for imaging of prostate cancer. Adv Urol. 2009;2009:1-12.

6. Heidenreich A, Aus G, Bolla M, et al. EAU guidelines on prostate cancer. Eur Urol. 2008;53:68-80.

7. Toegel S, Hoffmann O, Wadsak W, et al. Uptake of bone-seekers is solely associated with mineralisation! A study with ${ }^{99 \mathrm{~m} T c-M D P},{ }^{153} \mathrm{Sm}-$ EDTMP and ${ }^{18}$ F-fluoride on osteoblasts. Eur J Nucl Med Mol Imaging. 2006;33:491-494.

8. Ghosh A, Heston WDW. Tumor target prostate-specific membrane antigen (PSMA) and its regulation in prostate cancer. J Cell Biochem. 2004;91:528-539.

9. Israeli RS, Powell CT, Fair WR, Heston WD. Molecular cloning of a complementary DNA encoding prostate-specific membrane antigen. Cancer Res. 1993; 53:227-230.

10. Horoszewicz JS, Kawinski E, Murphy GP. Monoclonal antibodies to a new antigenic marker in epithelial prostatic cells and serum of prostatic cancer patients. Anticancer Res. 1987;7:927-935.

11. Silver DA, Pellicer I, Fair WR, Heston WD, Cordon-Cardo C. Prostate-specific membrane antigen expression in normal and malignant human tissues. Clin Cancer Res. 1997;3:81-85.

12. Perner S, Hofer MD, Kim R, et al. Prostate-specific membrane antigen expression as a predictor of prostate cancer progression. Hum Pathol. 2007;38:696-701.

13. Wright GL Jr, Grob BM, Haley C, et al. Upregulation of prostate-specific membrane antigen after androgen-deprivation therapy. Urology. 1996;48:326-334.
14. Sweat SD, Pacelli A, Murphy GP, Bostwick DG. Prostate-specific membrane antigen expression is greatest in prostate adenocarcinoma and lymph node metastases. Urology. 1998;52:637-640.

15. Ross JS, Sheehan CE, Fisher HA, et al. Correlation of primary tumor prostate specific membrane antigen expression with disease recurrence in prostate cancer. Clin Cancer Res. 2003;9:6357-6362.

16. Vallabhajosula S, Kuji I, Hamacher KA, et al. Pharmacokinetics and biodistribution of ${ }^{111} \mathrm{In}$ - and ${ }^{177} \mathrm{Lu}$-labeled J591 antibody specific for prostate-specific membrane antigen: prediction of ${ }^{90} \mathrm{Y}-\mathrm{J} 591$ radiation dosimetry based on ${ }^{111} \mathrm{In}$ or ${ }^{177}$ Lu? J Nucl Med. 2005;46:634-641.

17. Bander NH, Milowsky MI, Nanus DM, et al. Phase I trial results of lutetium-177 labeled J591, a monoclonal antibody to PSMA in patients with androgenindependent prostate cancer. J Clin Oncol. 2005;23:4591-4601.

18. Cho SY, Gage KL, Mease RC, et al. Biodistribution, tumor detection, and radiation dosimetry of ${ }^{18} \mathrm{~F}-\mathrm{DCFBC}$, a low-molecular-weight inhibitor of prostatespecific membrane antigen, in patients. J Nucl Med. 2012;53:1883-1891.

19. Afshar-Oromieh A, Zechmann CM, Malcher A. Comparison of PET imaging with a ${ }^{68} \mathrm{Ga}$-labelled PSMA ligand and ${ }^{18} \mathrm{~F}$-choline-based PET/CT for the diagnosis of recurrent prostate cancer. Eur J Nucl Med Mol Imaging. 2014;41:11-20.

20. Tiffany CW, Lapidus RG, Merion A, et al. Characterization of the enzymatic activity of PSMA: comparison with brain NAALADase. Prostate. 1999;39:28-35.

21. Pinto JT, Suffoletto BP, Bergin TM. Prostate-specific membrane antigen: a novel folate hydrolase in human prostatic carcinoma cells. Clin Cancer Res. 1996; 2:1445-1451.

22. Stoermer D, Liu Q, Hall MR, et al. Synthesis and biological evaluation of hydroxamate-based inhibitors of glutamate carboxypeptidase II. Bioorg Med Chem Lett. 2003;13:2097-2100.

23. Maresca KP, Hillier SM, Femia FJ, et al. A series of halogenated heterodimeric inhibitors of prostate-specific membrane antigen (PSMA) as radiolabeled probes for targeting prostate cancer. J Med Chem. 2009;52:347-357.

24. Hillier SM, Maresca KP, Femia FJ, et al. Preclinical evaluation of novel glutamateurea-lysine analogs that target prostate specific membrane antigen as molecular imaging pharmaceuticals for prostate cancer. Cancer Res. 2009;69:6932-6940.

25. Maresca KP, Hillier SM, Lu G, et al. Small molecule inhibitors of PSMA incorporating technetium-99m for imaging prostate cancer: effects of chelate design on pharmacokinetics. Inorg Chim Acta. 2012;389:168-175.

26. Hillier SM, Maresca KP, Lu G, et al. ${ }^{99 \mathrm{~m} T c-l a b e l e d ~ s m a l l-m o l e c u l e ~ i n h i b i t o r s ~ o f ~}$ prostate-specific membrane antigen for molecular imaging of prostate cancer. J Nucl Med. 2013;54:1369-1376.

27. Barrett JA, Coleman RE, Goldsmith SJ, et al. First-in-man evaluation of two high-affinity PSMA-avid small molecules for imaging prostate cancer. $J \mathrm{Nucl}$ Med. 2013;54:380-387.

28. Vallabhajosula S, Osborne JR, Nikolopoulou A, et al. Novel ${ }^{99 \mathrm{~m}}$ Tc-labeled small molecule inhibitors of prostate specific membrane antigen (PSMA): initial experience in healthy volunteers and men with metastatic prostate adenocarcinoma (PCa) [abstract]. Eur J Nucl Med Mol Imaging. 2011;38(suppl 2):S202.

29. Lu G, Maresca KP, Hillier SM, et al. Synthesis and SAR of ${ }^{99 \mathrm{~m}} \mathrm{Tc} / \mathrm{Re}-$ labeled small molecule prostate specific membrane antigen inhibitors with novel polar chelates. Bioorg Med Chem Lett. 2013;23:1557-1563.

30. The SAAM Institute, Inc. The SAAM Institute website. http://www.saam.com. Accessed October 8, 2014.

31. Stabin MG, Siegel JA. Physical models and dose factors for use in internal dose assessment. Health Phys. 2003;85:294-310.

32. Stabin MG, Sparks RB, Crowe E. OLINDA/EXM: the second generation personal computer software for internal dose assessment in nuclear medicine. $\mathrm{J} \mathrm{Nucl}$ Med. 2005;46:1023-1027.

33. Cloutier RJ, Smith SA, Watson EE, et al. Dose to the fetus from radionuclides in the bladder. Health Phys. 1973;25:147-161.

34. International Commission on Radiological Protection. Limits for Intakes of Radionuclides by Workers. ICRP publication 30. New York, NY: Pergamon Press; 1979.

35. Eder M, Eisenhut M, Babich JW, Haberkorn U. PSMA as a target for radiolabeled small molecules. Eur J Nucl Med Mol Imaging. 2013;40:819-823.

36. Vallabhajosula S, Osborne JR, Nikolopoulou A, et al. PSMA targeted SPECT imaging biomarker to detect local and metastatic prostate cancer (PCa): phase I studies with ${ }^{99 \mathrm{~m}}$ Tc-MIP-1404 [abstract]. J Nucl Med. 2013;54(suppl 2):281.

37. Goffin K, Joniau S, Tenke P, et al. A phase 2 study of ${ }^{99 \mathrm{~m}}$ Tc-trofolastat (MIP1404) to identify prostate cancer (PCa) in high-risk patients (pts) undergoing radical prostatectomy (RP) and extended pelvic lymph node (ePLN) dissection: an interim analysis [abstract]. J Nucl Med. 2014;55(suppl 1):15. 